\title{
IDENTIFIKASI LAPISAN RAWAN LONGSOR JALUR REL KERETA API ANTARA STASIUN CICAYUR DAN STASIUN PARUNG PANJANG, BANTEN
}

\author{
Febty Febriani*), Titi Anggono, Jauhari Arifin \\ ${ }^{1}$ Pusat Penelitian Fisika LIPI Kompleks Puspiptek Gdg 440-442, Serpong, Tangerang 15314 \\ Email: *) febty.febriani@lipi.go.id; febty82@gmail.com
}

\begin{abstract}
Abstrak
Telah dilakukan penelitian untuk mengidentifikasi lapisan rawan longsor pada jalur rel kereta api antara stasiun Cicayur dan stasiun Parung Panjang, Banten, yang merupakan stasiun-stasiun yang dilewati oleh commuter line dan kereta api lokal yang berangkat dari stasiun Parung Panjang menuju stasiun Tanah Abang dan sebaliknya. Lintasan commuter line ini merupakan jalur commuter line yang sibuk dan padat penumpang karena merupakan pilihan satu-satunya bagi penduduk Bumi Serpong Damai (BSD) dan sekitarnya jika ingin pergi menuju wilayah Jakarta, Bogor, Depok, Tangerang, Bekasi (Jabodetabek), dan sekitarnya dengan menggunakan kereta api. Penelitian dilakukan dengan menggunakan metode resistivitas konfigurasi dipole-dipole dan konfigurasi Wenner dengan masing-masing panjang lintasan adalah $240 \mathrm{~m}$ untuk konfigurasi dipole-dipole dan $20 \mathrm{~m}$ untuk konfigurasi Wenner. Data lapangan diolah dengan menggunakan program RES2DInv dan IP2WIN. Hasil pengolahan data menunjukkan bahwa nilai resistivitas batuan yang rendah di permukaan $(47.13 \Omega \mathrm{m})$ dan kemungkinan berhubungan dengan keberadaan batuaan gunung api dan batuan sedimen di daerah penelitian. Struktur batuan seperti ini berpeluang menimbulkan terjadinya tanah longsor jika kemampuan lapisan batuan untuk menahan resapan air hujan sudah melebihi ambang batas.
\end{abstract}

Kata Kunci: jalur rel kereta api, tanah longsor, metode resistivitas, Res2DInv, IP2Win

\begin{abstract}
The landslide prone area on the railway between the Cicayur and Parung Panjang stations, Banten, which lie on between the Tanah Abang and Parung Panjang stations, has been investigated. The railway track between Tanah Abang and Parung Panjang stations is the busy track since this track is passed by the commuter lines which have the route from the Bumi Serpong Damai (BSD) Serpong to the Jabodetabek (Jakarta, Bogor, Depok, Tangerang, and Bekasi). The investigation has been carried out by using direct current resistivity (DC resistivity) method (dipole-dipole and wenner arrays). The dipole-dipole and wenner arrays have $240 \mathrm{~m}$ and $20 \mathrm{~m}$ electrodes spacing, respectively. The resistivity data have been analyzed by using RES2DInv and IP2WIN programs. The result shows that the study area has low resistivity values $(47.13 \Omega \mathrm{m})$ at near surface and is possibly associated with the volcanic and sedimentary material in the study area. The area which consists of the volcanic and sedimentary material will be landslide prone area if the ability of the rock layer to resist the rainfall infiltration has exceeded its threshold.
\end{abstract}

Keyword: railway track, landslide, DC resistivity, RES2DInv, IP2Win

\section{Pendahuluan}

Metode resistivitas merupakan salah satu dari metode geofisika yang paling tua dan paling umum digunakan dalam bidang eksplorasi [1]. Metode resistivitas ini sering digunakan untuk eksplorasi mineral, hidrologi, lingkungan, pertanian, arkeologi, studi tanah longsor dan lain-lain [2]. Metode resistivititas adalah metode yang paling sering digunakan untuk studi dengan tujuan mengidentifikasi lapisan rawan longsor di suatu daerah karena metode mampu ini mengukur nilai resistivitas lapisan batuan serta geometri dari lapisan rawan longsor $[3,4,5,6,7]$.

Jalur kereta api stasiun Cicayur dan stasiun Parung Panjang menjadi bagian dari jalur kereta api ekonomi dan commuter line antara stasiun Tanah Abang dan stasiun Parung Panjang. Jalur kereta ini merupakan jalur kereta utama yang menghubungkan antara daerah 
Parung Panjang dan daerah Tanah Abang dengan menggunakan moda transportasi kereta api. Bagi para penduduk yang tinggal di kawasan Bumi Serpong Damai (BSD) Serpong dan sekitarnya, jalur kereta api Tanah Abang-Parung Panjang merupakan pilihan satu-satunya jika ingin pergi menuju wilayah Jakarta, Bogor, Depok, Tangerang, dan Bekasi (Jabodetabek) dengan menggunakan moda transportasi kereta api.

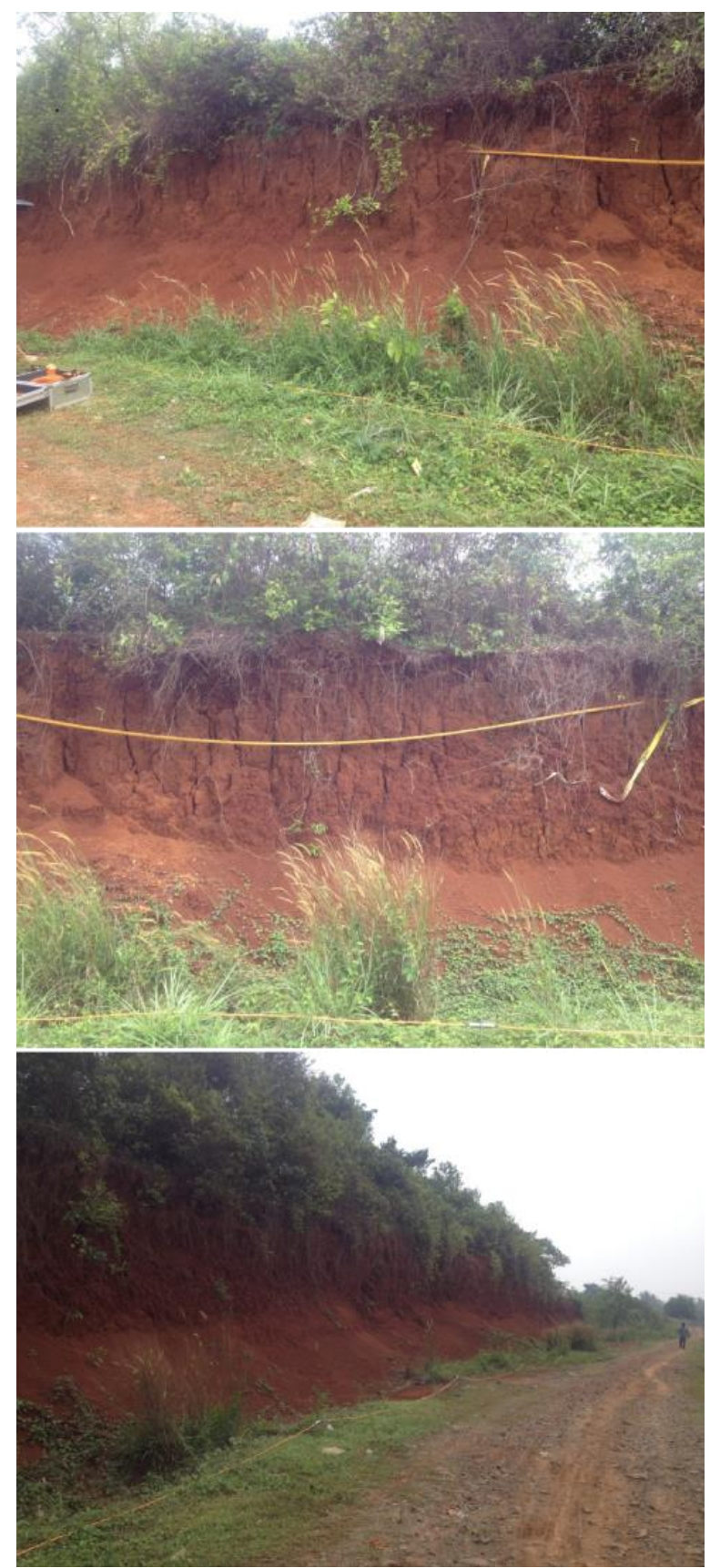

Gambar 1. Tebing yang bersisian dengan rel kereta api menuju stasiun Parung Panjang yang berada di lokasi penelitian

Pada jalur kereta api antara stasiun Cicayur dan stasiun Parung Panjang terdapat sungai kecil yang menjadi pembatas antara Provinsi Jawa Barat dan Provinsi Banten serta tebing dengan ketinggian sekitar dua meter seperti yang digambarkan oleh Gambar 1 . Lokasi tebing ini bersisian dengan jalur kereta api yang menghubungkan stasiun Cicayur dan stasiun Parung Panjang. Struktur lapisan batuan pada tebing ini bukan merupakan lapisan batuan yang kompak dan padat tetapi cenderung gembur.

Oleh karena itu, karena pentingnya keberadaan jalur kereta api ini bagi moda transportasi kereta api dari stasiun Parung Panjang menuju stasiun Tanah Abang, maka dilakukan penelitian untuk mengetahui kondisi lapisan tanah sepanjang lintasan kereta api yang menghubungkan stasiun Cicayur dan stasiun Parung Panjang dengan menggunakan metode resistivitas.

\section{Metode Penelitian}

Penelitian ini dilakukan di daerah Parung Panjang, Bogor, Jawa Barat, seperti yang ditunjukkan oleh Gambar 2. Koordinat lokasi penelitian adalah $106.579^{\circ}$ BT dan $6.344^{\circ}$ LS (Gambar 2). Penelitian dilakukan pada tanggal 12 November 2014.

Secara geologi permukaan, daerah penelitian didominasi oleh aluvium, batuan gunungapi, dan batuan sedimen dari Formasi Bojongmanik, Formasi Genteng, Formasi Serpong, Formasi Rengganis. Formasi Bojongmanik ini merupakan perselingan antara batupasir dan batulempung dengan sisipan batugamping. Formasi Serpong merupakan perselingan konglomerat, batupasir, batulanau, dan batu lempung dengan sisa tanaman, konglomerat batuapaung, dan tuf batuapung. Sedangkan Formasi Rengganis terdiri dari batupasir halus kasar konglomeratan dan batu lempung [8]. Kondisi geologi permukaan daerah penelitian ini digambarkan pada Gambar 3.

Metode resistivitas adalah salah satu metode untuk mengetahui perubahan tahanan jenis lapisan batuan di dawah permukaan tanah dengan cara mengalirkan arus listrik DC (direct current) yang mempunyai tekanan tinggi ke dalam tanah. Metode geolistrik terbagi atas 3 jenis yaitu metode potensial diri, metode induksi polarisasi, dan metode resistivitas [9]. Penelitian ini menggunakan metode resistivitas dengan konfigurasi dipole-dipole dan konfigurasi Wenner.

Penelitian dengan menggunakan metode resistivitas konfigurasi dipole-dipole dan konfigurasi Wenner ini dilakukan di lokasi yang sama dengan menggunakan alat geolistrik dengan merk ARES. 
Panjang lintasan survey dengan metode resistivitas konfigurasi dipole-dipole adalah $240 \mathrm{~m}$ sedangkan panjang lintasan survey dengan metode resistivitas tahanan jenis konfigurasi Wenner adalah $20 \mathrm{~m}$. Metode penelitian dalam studi ini ditunjukkan oleh langkah penelitian pada Gambar 4.

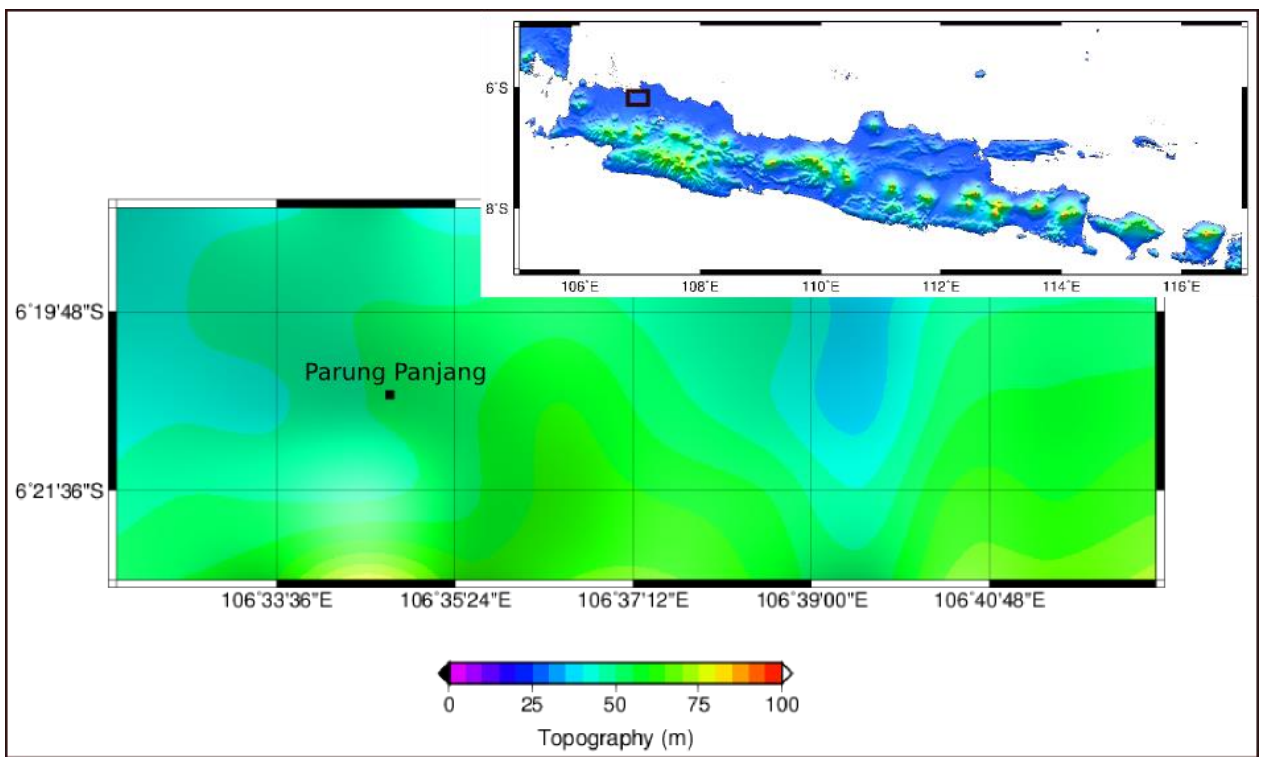

Gambar 2. Lokasi penelitian

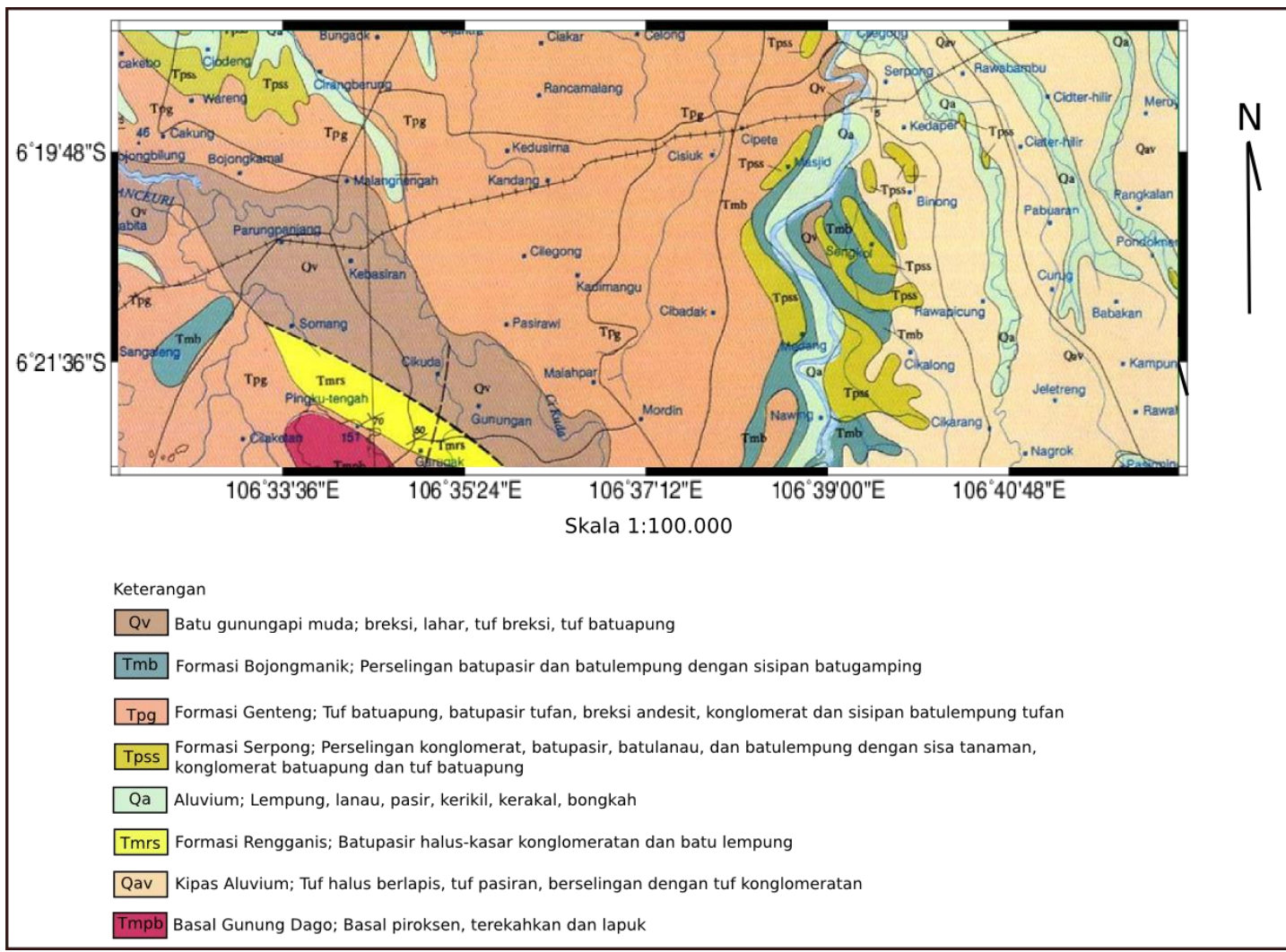

Gambar 3. Kondisi geologi permukaan daerah penelitian 


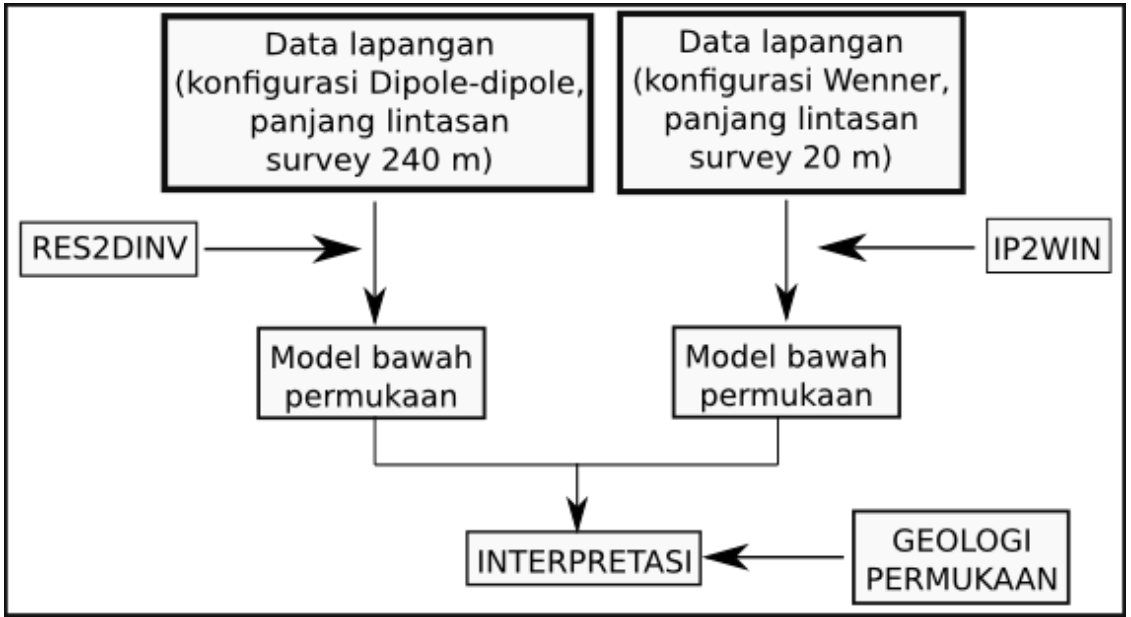

Gambar 4. Alur penelitian yang digunakan dalam studi ini

\section{Hasil dan Pembahasan}

Data lapangan dari survey dengan menggunakan metode resistivitas konfigurasi dipole-dipole diolah dengan menggunakan program RES2DInv.

Gambar 5 menunjukkan hasil pemodelan bawah permukaan daerah penelitian dengan menggunakan metode resistivitas konfigurasi dipole-dipole. Panel pertama dari Gambar 4 adalah model 2 dimensi dari data lapangan hasil pengukuran dengan menggunakan metode geolistrik konfigurasi dipole-dipole. Panel kedua dari Gambar 4 adalah model 2 dimensi dari data hasil perhitungan data lapangan. Sedangkan panel ketiga adalah model inversi dari data lapangan pengukuran metode resistivitas konfigurasi dipole-dipole.

Model inversi dari data lapangan metode resistivitas konfigurasi dipole-dipole menunjukkan di permukaan sampai dengan kedalaman sekitar $10 \mathrm{~m}$, nilai resistivitas daerah penelitian sekitar 100-500 $\Omega \mathrm{m}$. Nilai resistivitas yang paling tinggi ditemukan pada lintasan antara 120-160 m mulai dari permukaan hingga kedalaman sekitar $13 \mathrm{~m}$.

Di bawah lapisan ini terdapat lapisan batuan yang mempunyai nilai resistivitas dengan rentang 20-40 $\Omega \mathrm{m}$. Sedangkan pada kedalaman yang lebih dalam, nilai resistivitas lapisan batuan di daerah penelitian didominasi oleh batuan-batuan yang mempunyai nilai resistivitas yang rendah, berkisar antara 1-10 $\Omega \mathrm{m}$.

Sebagai pembanding dari data lapangan yang didapatkan dengan menggunakan metode resistivitas konfigurasi dipole-dipole, penelitian dengan menggunakan metode resistivitas konfigurasi Wenner juga dilakukan di lokasi yang sama dengan lokasi pengambilan data metode resisitivitas konfigurasi dipole-dipole. Pengolahan data lapangan dari metode resistivitas konfigurasi Wenner menggunakan program IP2WIN.

Model 1 dimensi dari konfigurasi Wenner ini digambarkan pada Gambar 6. Gambar 6 menunjukkan bahwa di permukaan nilai resistivitas batuannya adalah 47.13 Ohm m. Gambar 5 tidak menunjukkan adanya lapisan ini karena kemungkinan lapisan ini hanya sampai pada kedalaman $0.5 \mathrm{~m}$. Pada kedalaman 0.5-6 m, nilai resistivitas lapisan batuan adalah 212.81 $\Omega \mathrm{m}$. Lapisan ketiga pada kedalaman dengan rentang 6-14 m mempunyai nilai resistivitas sebesar 35.69 $\Omega \mathrm{m}$ dan lapisan yang paling dalam mempunyai nilai resistivitas sekitar $12.86 \Omega \mathrm{m}$.

Lapisan dengan nilai resistivitas batuan sekitar 47.13 $\Omega \mathrm{m}$ ini kemungkinan berhubungan dengan keberadaan batuaan gunung api dan batuan sedimen misalnya batuan tuf, batupasir, batulempung dan lain-lain yang mendominasi di daerah penelitian.

Secara teori, lapisan rawan longsor pada umumnya ditandai dengan adanya lapisan batuan yang umumnya mempunyai nilai resistivitas antara 10-30 $\Omega \mathrm{m}$, yang umumnya adalah lapisan yang mengandung material lempung dan atau air [3]. Namun, pada lapisan batuan dengan kandungan material lempung yang kompak, nilai resistivitas lapisan rawan longsor bisa mencapai sekitar $75 \Omega \mathrm{m}$ [3]. Sedangkan pada batuan metamorf, adanya efek gravitasi bisa menyebabkan naiknya atau turunnnya nilai resistivitas batuan tergantung dari ada atau tidaknya kandungan air yang cukup banyak dalam lapisan batuan tersebut $[10,11]$. 

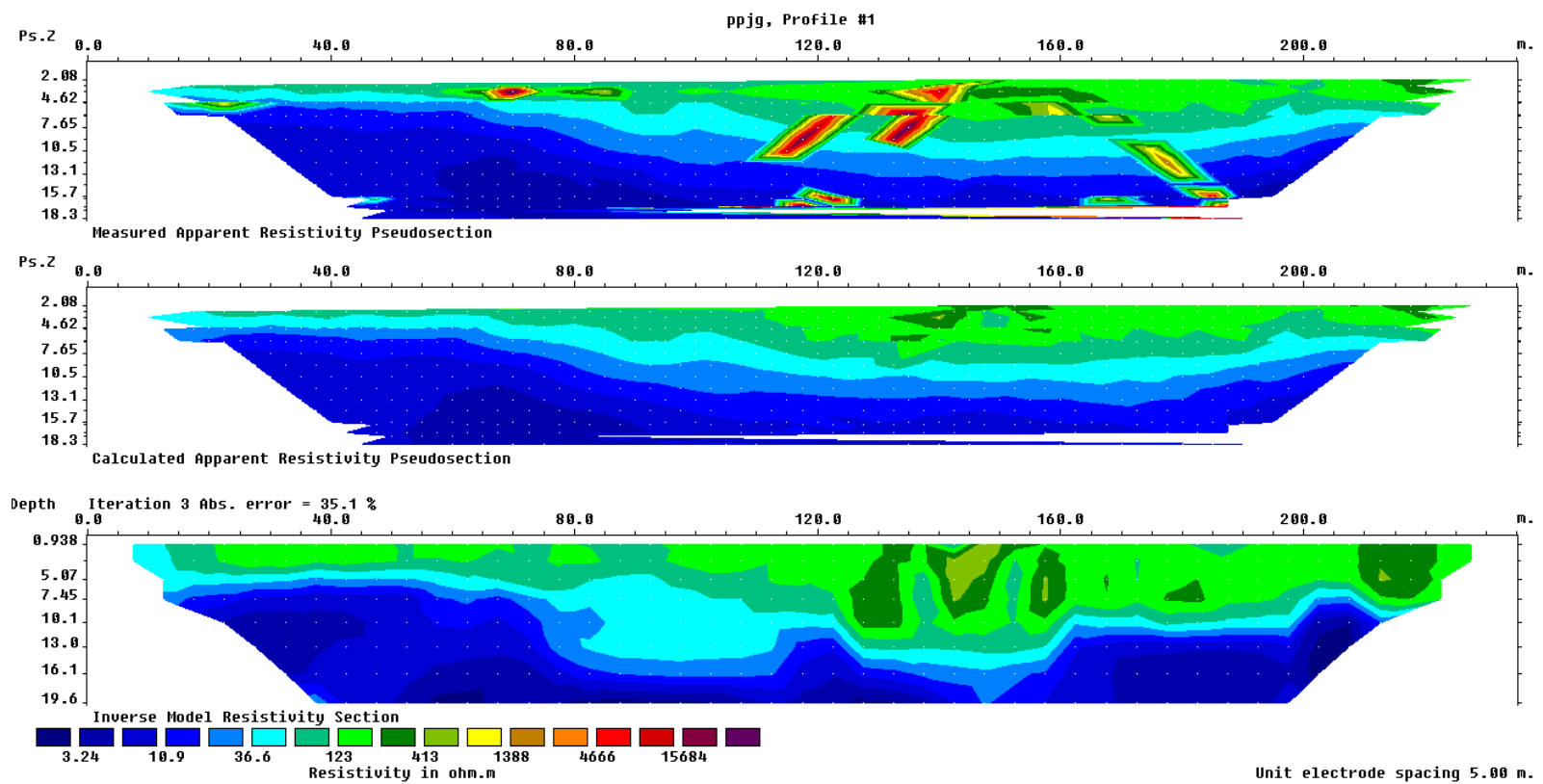

Gambar 5. Hasil pemodelan bawah permukaan daerah penelitian dengan menggunakan metode resistivitas konfigurasi dipole-dipole. Panel pertama adalah model 2 dimensi dari data lapangan. Panel kedua adalah model 2 dimensi dari data perhitungan data lapangan. Panel ketiga adalah model inversi dari data lapangan. Sumbu x dari ketiga panel menandakan kedalaman sedangkan sumbu y menandakan panjang lintasan. Satuan yang digunakan oleh sumbu x dan y adalah dalam $\mathrm{m}$.

Melihat nilai resistivitas batuannya, lapisan batuan yang di permukaan ini berpeluang menimbulkan terjadinya tanah longsor. Hal ini akan terjadi jika kemampuan lapisan batuan untuk menahan resapan air hujan sudah melebihi ambang batas.

Sedangkan nilai resistivitas batuan yang cukup tinggi pada kedalaman mulai dari 0.5-6 m kemungkinan berhubungan dengan keberadaan kondisi batuan yang sedikit mengandung material sedimen dan atau air.

Pada kedalaman yang lebih dalam, nilai resistivitas batuan yang rendah di kemungkinan berhubungan dengan keberadaan sumber air tanah. Hal ini sesuai dengan keberadaan sungai kecil yang menjadi pembatas antara Provinsi Banten dan Provinsi Jawa Barat yang berada kurang lebih $5 \mathrm{~m}$ dari daerah penelitian.

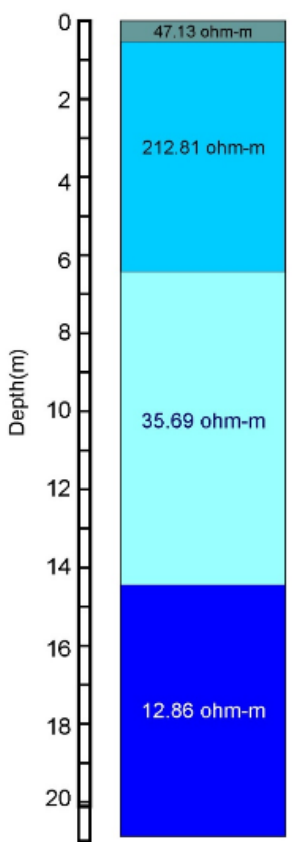

Gambar 6. Model 1 dimensi lapisan bawah permukaan daerah penelitian dengan menggunakan metode resistivitas dengan konfigurasi Wenner 


\section{Kesimpulan}

Penelitian ini dilakukan untuk mengidentifikasi lapisan rawan longsor di daerah antara stasiun Cicayur dan stasiun Parung Panjang, Banten. Penelitian dilakukan dengan menggunakan metode resistivitas. Hasil penelitian menunjukkan nilai resistivitas batuan di permukaan sekitar $47.13 \Omega \mathrm{m}$. Lapisan kedua mempunyai nilai resistivitas sekitar 100-500 $\Omega \mathrm{m}$ dan semakin ke dalam nilai resistivitas batuan di daerah penelitian semakin rendah. Lapisan permukaan dengan nilai resistivitas sekitar $47.13 \Omega \mathrm{m}$ ini kemungkinan berhubungan dengan keberadaan batuan sedimen dan batuan gunung api yang akan berpeluang menimbulkan terjadinya tanah longsor jika kemampuan lapisan batuan untuk menahan resapan air hujan sudah melebihi ambang batas.

Di masa yang akan datang, di daerah ini perlu dilakukan penelitian geofisika dengan menggunakan metode lainnya seperti metode seismik refraksi, tomografi seismik, tomografi resisitivitas dan lain-lain sehingga identifikasi lapisan rawan longsor di daerah ini dapat dilakukan dengan maksimal.

\section{Ucapan Terimakasih}

Penelitian ini merupakan kerjasama antara kelompok penelitian geofisika Pusat Penelitian Fisika LIPI dan Pusat Penelitian dan Pengembangan Dinas Perhubungan.

\section{Daftar Acuan}

[1] J.M. Reynolds. An Introduction to Applied and Environmental Geophysics. 2nd edition. John Wiley\&Sons, England (2011).

[2] M.H. Loke, J.E. Chambers, D>F. Rucker, O. Kuras, and P.B. Wilkinson, Recent developments in the direct-current geoelectrical imaging method, J. Appl. Geophys. 95 (2013), p. $135-156$.

[3] D. Jongmans and S. Garambois, Geophysical investigation of landslides; a review, Bulletin de la Societe Geologique de France. 178(2) (2007), p. 101-112.

[4] M. Gallipoli, Lapenna, V., Lorenzo, P., Mucciarelli, M., Perrone, A., Piscitelli, S., and Sdao, F., Comparison of geological and geophysical prospecting techniques in the study of a landslide in southern Italy, Eur. J. Environ. Eng. Geophys. 4 (2000), p. 117-128.

[5] H. J. Mauritsch, Seiberl, W., Arndt, R., Romer, A., Schneiderbauer, K., and Sendlhofer, G. P., Geophysical investigations of large landslides in the Carnic region of southern Austria, Eng. Geol. 56 (2000), p. 373-388.
[6] V. Lapenna, Lorenzo, P., Perrone, A., Piscitelli, S., Rizzo, E. and Sado, F., High-resolution geoelectrical tomographies in the study of the Giarrossa landslide (Potenza, Basilicata), B. Eng. Geol. Environ. 62 (2003), p. 259-268.

[7] A. Perrone, Lannuzi, A., Lapenna, V., Lorenzo, P., Piscitelli, S., Rizzo, E., and Sdao, F, High-resolution electrical imaging of the Varco d'Izzo earthflow (southern italy), J. Appl. Geophys. 56 (2004), p. 17-29.

[8] T. Turkandi, Sidarto, D.A. Aguztiyanto, M.M.P. Hadiwidjoyo, Peta Geologi Lembar Jakarta dan Kepulauan Seribu, Jawa Skala 1:100.000, Pusat Penelitian dan Pengembangan Geologi, Bandung (1992).

[9] W.M. Telford, L.P. Geldart, dan R.E. Sheriff. Applied Geophysics. Cambridge University Press, Cambridge (1990), 792p.

[10] O. Meric, S. Garambois, D. Jongmans, M. Wathelet, J.L. Chatelain, and J.M. Vengeon, Application of geophysical methods for the investigation of the large gravitational mass movement of Sechilienne, France, Canada Geotech. J. 42 (2005), p. 1105-1115.

[11] T. Lebourg, S. Binet, E. Trice, H. Jomard, S. El Bedoui, Geophysical survey to estimate the 3D sliding surface and the 4D evolution of the water pressure on part of a deep seated landslide, Terra Nova 17 (2005), p. 399-406. 